Original Article

\title{
Beneficial effects of andrographolide in a rat model of autoimmune myocarditis and its effects on PI3K/Akt pathway
}

\author{
Qi Zhang, Li-qun Hu, Hong-qi Li, Jun Wu, Na-na-Bian, and Guang Yan* \\ Department of Geriatrics, Anhui Provincial Hospital, The First Affiliated Hospital of University of Science and Technology of China, Anhui Institute of Cardio- \\ vascular Disease, Hefei 230001, China
}

\section{ARTICLE INFO}

Received April 16, 2018

Revised June 29, 2018

Accepted July 20, 2018

\section{*Correspondence \\ Guang Yan \\ E-mail:yanguang399@sina.com}

\section{Key Words}

Akt

Andrographolide

Autoimmune myocarditis

$\mathrm{PI} 3 \mathrm{~K}$

\begin{abstract}
The study is to investigate effects of andrographolide on experimental autoimmune myocarditis (EAM). Lewis rats were immunized on day 0 with porcine cardiac myosin to establish EAM. The EAM rats were treated with either andrographolide $(25,50,100 \mathrm{mg} / \mathrm{kg} /$ day) or vehicle for 21 days. An antigen-specific splenocytes proliferation assay was performed by using the cells from control rats immunized with cardiac myosin. Survival rates, myocardial pathology and myocardial functional parameters (left ventricle end-diastolic pressure, $\pm \mathrm{dP} / \mathrm{dt}$ and left ventricular internal dimension) of EAM rats received andrographolide were significantly improved. Andrographolide treatment caused an decrease in the infiltration of $\mathrm{CD}^{+}$ and $\mathrm{CD} 14^{+}$positive cells in myocardial tissue. Moreover, andrographolide treatment caused a reduction in the plasma levels of tumor necrosis factor-alpha, interleukin-17 (IL-17) and myosin-antibody, and an increase in the level of IL-10 in EAM rats. Oral administration of andrographolide resulted in the decreased expression of $\mathrm{p}-\mathrm{PI} 3 \mathrm{~K}$ p-Akt without any change of PI3K and Akt. Further results indicate andrographolide significantly inhibited myosin-induced proliferation in splenocytes, and this effect was inhibited by co-treatment of SC79 (Akt activator). Our data indicate andrographolide inhibits development of EAM, and this beneficial effect may be due to powerful anti-inflammatory activity and inhibitory effect on PI3K/Akt pathway.
\end{abstract}

\section{INTRODUCTION}

Myocarditis is a non-ischemic heart disease with rapidly progressive heart failure, arrhythmias, sudden cardiac death, and is a major cause of cardiomyopathies-induced death in younger [1]. A writing group convened by the GBD 2010 Study has estimated the burden of myocarditis as a percentage of prevalent heart failure varied by age and region from $0.5 \%$ to $4.0 \%$ [2]. At present, there is no specific therapy for myocarditis. In most cases, rest cure is the main strategy, and supplied with symptomatic therapies for arrhythmia, heart failure and cardiac shock.

Myocarditis is an inflammation of myocardium, and can be induced by autoimmune disease, infection and cardiotoxic agents
[3]. Inflammatory response directly deteriorates cardiac function and induces acute heart failure, chest pain and life threatening arrhythmias [4]. Phosphatidylinositol-3-kinase (PI3K)/Protein kinase B (Akt) signaling pathway is widely involved in the development of inflammatory diseases. The pathway has been identified as a central mediator of physiological cardiac hypertrophy [5]. Dysfunctional PI3K pathway has been broadly observed and demonstrated in angiocardiopathy [6]. In a recent published report, it has confirmed blocking PI3K/Akt pathway effectively inhibited development of myocarditis in animal models [7].

Andrographolide is a natural diterpenoid extracted from Andrographis paniculata, which traditionally used as an herbal medicine in China and Southeast Asia for thousands of years.
This is an Open Access article distributed under the terms of the Creative Commons Attribution Non-Commercial License, which permits unrestricted non-commercial use, distribution, and reproduction in any medium, provided the original work is properly cited. Copyright @ Korean J Physiol Pharmacol, pISSN 1226-4512, elSSN 2093-3827
Author contributions: Q.Z. and L.Q.H. conceived performed statistical analyses, and wrote the paper; Q.Z., H.Q.L., J.W. and N.N.B. performed the experiments; G.Y. provided necessary resources, designed the study protocol and analyzed the data. 
It has been previously reported andrographolide displays antioxidant, anti-inflammatory, anti-cancer, hypoglycemic, and antivirus activity [8]. Moreover, andrographolide has been concluded to attenuate pathological cardiac hypertrophy in high fat diet fed mice, and exhibits anti-inflammatory and anticoagulant properties by inhibiting Mitogen-activated protein kinase (MAPK) and nuclear transcription factor- $\kappa \mathrm{B}(\mathrm{NF}-\kappa \mathrm{B})$ pathways in LPS-treated cardiac microvascular endothelial cells $[9,10]$. It is of interest to see andrographolide inhibits PI3K/Akt pathway in animal models and cultured cells, inducing a lot of pharmacological actions, such as inhibiting tumor cells growth, migration, invasion, and modulating the innate and adaptive immune responses [11,12]. However, it is still unclear whether andrographolide has a protective effect on myocarditis. Experimental autoimmune myocarditis (EAM) in rats is a well known model characterized by extensive myocardial necrosis, heart failure, which is extremely similar to that observed in clinical patients. Moreover, EAM shows progress into clinic pathological status (enlargement of heart, dilatation of ventricles, diffuse and extensive myocardial inflammation), which is similar to dilated cardiomyopathy in chronic phase [13]. Therefore, in present study, we used EAM model to evaluate the efficacy of andrographolide.

\section{METHODS}

\section{Animals}

The Lewis rats (male, eight weeks old) were purchased from Model Animal Research Center of Nanjing University (Nanjing, China), and placed in the animal house under controlled conditions of $25 \pm 2^{\circ} \mathrm{C}$, relative humidity of $60 \pm 5 \%$ and a light-dark cycle of 12:12 h. All rats were fed with food pellets and water ad libitum. The current study was approved by the Animal Ethics Committee of Anhui Provincial Hospital.

\section{Induction of experimental autoimmune myocarditis}

Purified porcine cardiac myosin (Sigma Chemical Co., St. Louis, MO, USA) was dissolved in $0.01 \mathrm{M}$ phosphate-buffered saline (PBS) and emulsified with an equal volume of complete Freund's adjuvant (CFA, Difco, Sparks, MD, USA) supplemented with mycobacterium tuberculosis H37RA (10 mg/ml, Difco). $0.2 \mathrm{ml}$ of emulsion was injected into the footpads of rats subcutaneously. For the control group, the rats received CFA in same manner. Following injection, a total of 56 rats were divided into several groups: control group $(\mathrm{n}=6)$, EAM group $(\mathrm{n}=10)$, andrographolide (purity $>98 \%$; Sigma-Aldrich, St. Louis, MO, USA) groups $(25,50,100 \mathrm{mg} / \mathrm{kg}, \mathrm{n}=3 \times 10)$ and losartan (Los, Aladdin biotechnology co., LTD; ShangHai, China) group (10 mg/kg, n = 10). After immunization, the rats were orally administrated with drugs or vehicle (control group) for 21 days.

\section{Assessment of myocardial functions}

To evaluate myocardial function, all rats were anesthetized with $2 \%$ halothane in oxygen during the surgical procedure. A catheter-tip transducer (Miller SPR-524; Miller Instruments, Houston, TX) was introduced into the left ventricle through the right carotid artery. Cardiac function parameters, including left ventricle end-diastolic pressure (LVEDP), heart rate (HR), and \pm $\mathrm{dP} / \mathrm{dt}$ were measured and recorded. An echocardiography system (NEMIO SSA-550A; Toshiba Medical Systems) with a dynamically focused $14 \mathrm{MHz}$ linear-array transducer and $7 \mathrm{MHz}$ sector transducer was used. Measurements were performed for at least ten beats in a blinded fashion, and repeated twice. Left ventricular internal dimension in diastole (LVDD) and left ventricular internal dimension in systole (LVDS) were measured. Ejection fraction (EF) was calculated according to the formula: EF $(\%)=\left(\mathrm{LVDd}^{3}-\right.$ $\left.\mathrm{LVDs}^{3}\right) / \mathrm{LVDd}^{3}$. Following that, the rats were sacrificed and hearts were removed, weighed and harvested.

\section{Anti-cardiac myosin antibody and inflammatory cytokines levels}

Blood was collected from femoral artery of rats and serum was prepared. The cytokines levels were measured by using ELISA kits according to the instructions. The kits of tumor necrosis factor-alpha (TNF-alpha), Interleukin-17 (IL-17) and IL-10 were products of R\&D Systems (Minneapolis, MN, USA). Moreover, the level of anti-cardiac myosin was determined by a previously published method [14].

\section{Cell proliferation assay}

Antigen-specific splenocytes proliferation was examined. In brief, splenocytes were isolated from the rats with myocarditis. The cells were cultured in a 96-well plates in RPMI-1640 (Invitrogen) supplemented with $10 \%$ fetal bovine serum and $1 \%$ penicillin/streptomycin solution. Following that, the cells were pretreated with andrographolide $(10,20$ and $40 \mu \mathrm{M})$ or Los $(10 \mu \mathrm{M})$ for $60 \mathrm{~min}$, and then they were treated with porcine heart myosin $(20$ $\mu \mathrm{g} / \mathrm{ml}$ ) for $48 \mathrm{~h}$. The proliferation of splenocytes was determined by a MTT assay.

\section{Histological analysis}

The excised myocardium was kept in formalin and then the sections were embedded in paraffin. The heart tissue was sectioned ( $4 \mu \mathrm{m}$ thick) and stained with hematoxylin and eosin. The sections were scored for myocarditis as follows: 0 , no infiltration or necrosis; 1 , between $1 \%$ and $25 \%$ infiltration or necrosis per section; 2, between $26 \%$ and $50 \%$ infiltration or necrosis per section; 3 , between $51 \%$ and $74 \%$ infiltration or necrosis per section; and 4 , between $75 \%$ and $100 \%$ infiltration or necrosis per section. The 
sections were examined by light microscopy and all histological evaluations were done by our laboratory technician who didn't know the groups information. Moreover, the area of inflammatory cells was evaluated by image pro plus software ( 6.0 version), which were showed as the ratio of area of inflammatory cells to that of total area.

\section{Immunohistochemical analysis}

Formalin-fixed and paraffin-embedded cardiac tissue sections were used for immunostaining. Briefly, the sections were incubated with anti-CD3 ${ }^{+}$(BD Biosciences, San Jose, CA, USA), or anti$\mathrm{CD}_{14}{ }^{+}$(BD Biosciences) antibodies, followed by incubation with HRP-linked rabbit anti-mouse IgG. The reaction products were visualized by using $0.5 \%$ diaminobenzidine and $0.03 \%$ hydrogen peroxide. The numbers of positive-stained cells were determined in ten randomly selected fields by a professional staff, who didn't know the grouped details.

\section{Western blotting}

Myocardial tissue samples were homogenized with lysis buffer, and the protein was extracted. Protein concentrations were measured by the bicinchoninic acid method. The samples were separated by SDS-PAGE and identified with following antibodies: PI3K, phosphorylated PI3K (p-PI3K), Akt and p-Akt (Santa Cruz
Biotechnology). After incubation with HRP-coupled secondary antibody (Santa Cruz Biotechnology), the bands were visualized with a chemiluminescence developing agents (Amersham Biosciences, UK). GAPDH was probed in the blots as internal control for loading. Results were semi-quantified as optical density band area by the Image J.

\section{Statistical analysis}

Data are presented as mean \pm S.D. Statistical analysis of differences between the groups was performed using one-way analysis of variance, followed by Tukey's multiple comparison test (SPSS 15.0, SPSS Inc., Chicago, IL, USA). Kruskal-Wallis test was used to analyze survival times, as multiple groups were used. A value of $\mathrm{p}<0.05$ was considered statistically.

\section{RESULTS}

\section{Effects of andrographolide on mortality, myocardial functions of EAM rats}

As seen in Fig. 1, survival curves showed protective effects of andrographolide on EAM rats. Myocarditis rats given vehicle had five deaths after myosin injection, whereas those treated with andrographolide $(50,100 \mathrm{mg} / \mathrm{kg}$ ) showed three and one deaths,
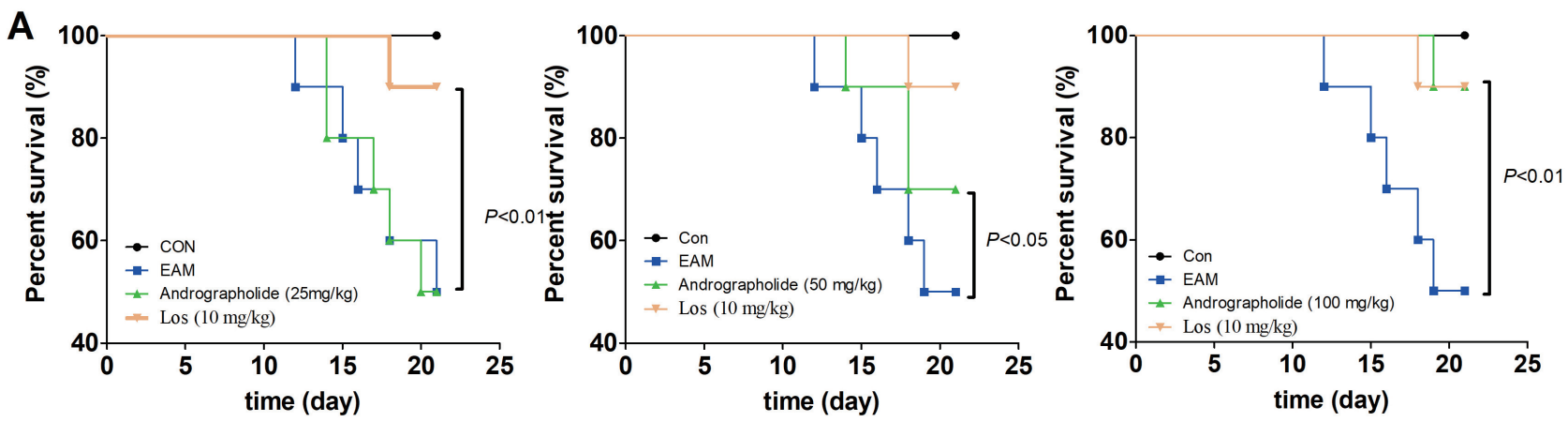

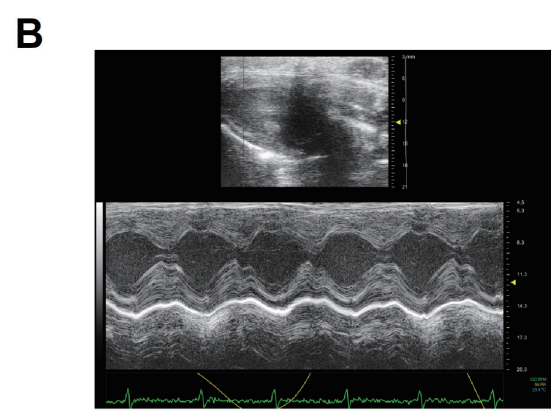

Con

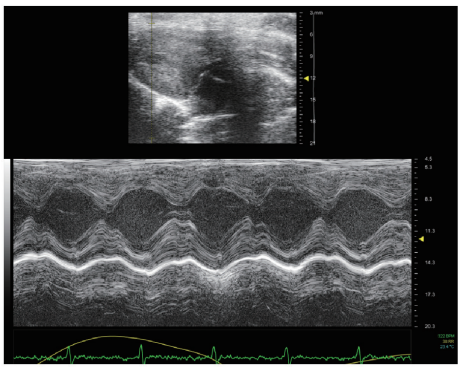

EAM

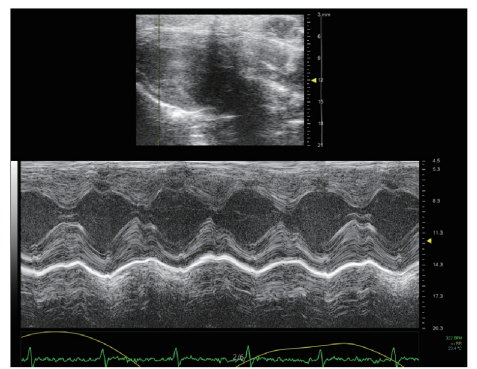

Andrographolide $50 \mathrm{mg} / \mathrm{kg}$

Fig. 1. Effects of andrographolide on mortality of EAM rats. (A) Survival curves of EAM rats. (B) Representative echocardiogram of M-mode on day 21. Control group includes six rats, whereas other groups include ten rats for each. Con: control; EAM: experimental autoimmune myocarditis; Los: losartan. 
respectively. The 21-day mortality was $50.0 \%$ in the EAM group, and $10.0 \%$ in andrographolide $(100 \mathrm{mg} / \mathrm{kg})$ group. Similar observation was presented in Los group compared with that of EAM group. As shown in Table 1, the cardiac function parameters, such as LVEDP, LVDS, HW/BW were significantly higher, and $\pm \mathrm{dP} /$ dt \& EF were significantly lower in EAM model compared with control ( $\mathrm{p}<0.05)$. However, compared with vehicle-treated EAM rats, treatment of andrographolide or Los significantly decreased LVEDP, LVDS, HW/BW, and increased $\pm \mathrm{dP} / \mathrm{dt}$ and $\mathrm{EF}(\mathrm{p}<0.05)$.

\section{Effects of andrographolide on myocardial histopathology of EAM rats}

As seen in Fig. 2, there were increased infiltration of inflammatory cells in EAM groups compared with control group (Fig. $2, \mathrm{p}<0.01)$. However, treatment of andrographolide $(50,100 \mathrm{mg} /$ $\mathrm{kg}$ ) and Los obviously inhibited infiltration of inflammatory cells in myocardial tissue $(\mathrm{p}<0.01)$. Our data suggest andrographolide effectively improves cardiac pathological performance of EAM

Table 1. Parameters of cardiac function at day 21 after myosin injection

\begin{tabular}{|c|c|c|c|c|c|c|c|}
\hline \multirow{2}{*}{\multicolumn{2}{|c|}{ Parameters }} & \multirow{2}{*}{ Con } & \multirow{2}{*}{ EAM } & \multicolumn{3}{|c|}{ Andrographolide (mg/kg) } & \multirow{2}{*}{$\frac{\operatorname{Los}(\mathrm{mg} / \mathrm{kg})}{10}$} \\
\hline & & & & 25 & 50 & 100 & \\
\hline LVEDP & $\mathrm{mm} \mathrm{Hg}$ & $3.29 \pm 1.2$ & $22.19 \pm 6.2^{\# \#}$ & $19.24 \pm 5.2$ & $14.53 \pm 4.9^{* *}$ & $11.33 \pm 5.2^{* *}$ & $9.29 \pm 6.6^{* *}$ \\
\hline$+\mathrm{dP} / \mathrm{dt}$ & $\mathrm{mm} \mathrm{Hg} / \mathrm{s}$ & $8264 \pm 1223$ & $2128 \pm 366^{\# \#}$ & $2917 \pm 423^{*}$ & $3735 \pm 786^{* *}$ & $5432 \pm 878^{* *}$ & $6425 \pm 1005^{* *}$ \\
\hline$-\mathrm{dP} / \mathrm{dt}$ & $\mathrm{mm} \mathrm{Hg} / \mathrm{s}$ & $7864 \pm 1223$ & $2001 \pm 298^{\# \#}$ & $2719 \pm 379^{*}$ & $3354 \pm 425^{* *}$ & $4725 \pm 564^{* *}$ & $5508 \pm 728^{* *}$ \\
\hline $\mathrm{HR}$ & beats/min & $327 \pm 15.2$ & $315 \pm 18.7$ & $309 \pm 22.4$ & $312 \pm 17.7$ & $325 \pm 17.4$ & $321 \pm 14.5$ \\
\hline LVDD & $\mathrm{mm}$ & $7.9 \pm 0.8$ & $7.5 \pm 1.2$ & $7.4 \pm 1.0$ & $7.2 \pm 1.1$ & $7.6 \pm 1.5$ & $7.5 \pm 0.9$ \\
\hline LVDS & $\mathrm{mm}$ & $4.2 \pm 0.6$ & $6.9 \pm 0.9^{\# \#}$ & $6.2 \pm 0.7$ & $5.4 \pm 1.3$ & $4.7 \pm 0.6^{* *}$ & $4.6 \pm 0.8^{* *}$ \\
\hline EF & $\%$ & $82.0 \pm 4.6$ & $20.2 \pm 2.6^{\# \#}$ & $43.6 \pm 7.5^{* *}$ & $64.4 \pm 5.7^{* *}$ & $72.9 \pm 3.7^{* *}$ & $78.4 \pm 3.3^{* *}$ \\
\hline HW/BW & $\%$ & $3.5 \pm 0.4$ & $6.1 \pm 0.7^{\# \#}$ & $5.5 \pm 0.5^{*}$ & $4.8 \pm 1.4^{* *}$ & $4.1 \pm 0.8^{* *}$ & $4.4 \pm 1.3^{* *}$ \\
\hline
\end{tabular}

Results are presented as the mean \pm S.D. $N=6$-9. LVEDP, left ventricular end-diastolic pressure; $\pm d P / d t$, rate of intra-ventricular pressure rise and decline; HR, heart rate; LVDD, left ventricular dimension in diastole; LVDS, left ventricular dimension in systole; EF, ejection fraction; Con: control; EAM: experimental autoimmune myocarditis; Los: losartan. ${ }^{\sharp *} p<0.01$, compared with Con; ${ }^{*} p<0.05,{ }^{* *} p<0.01$, compared with EAM.
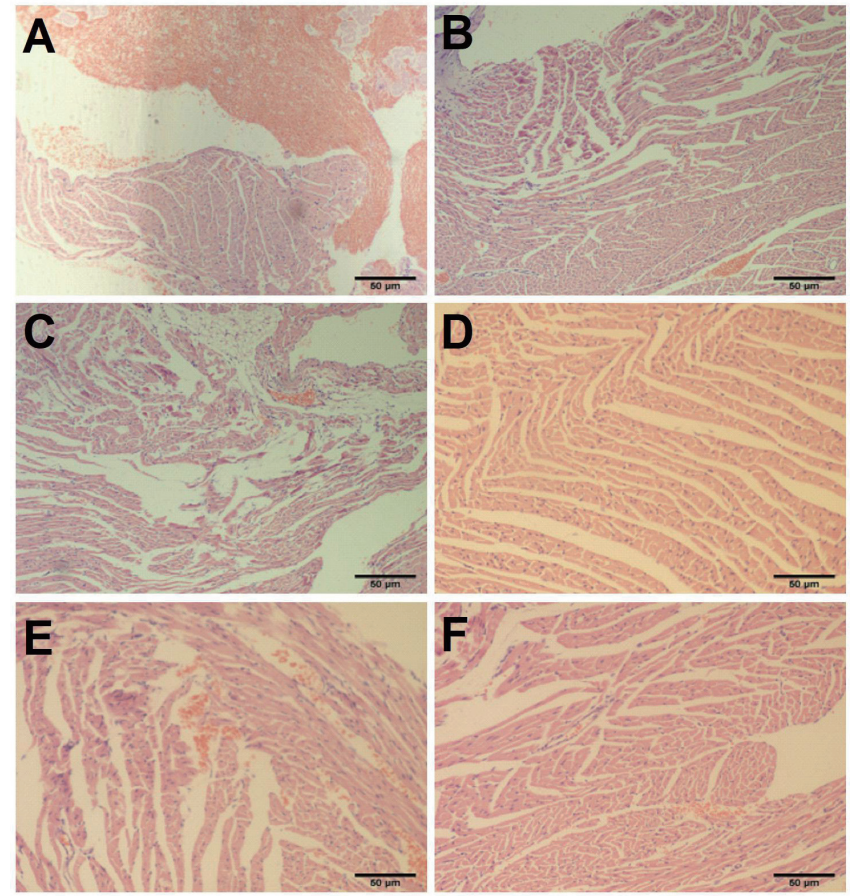

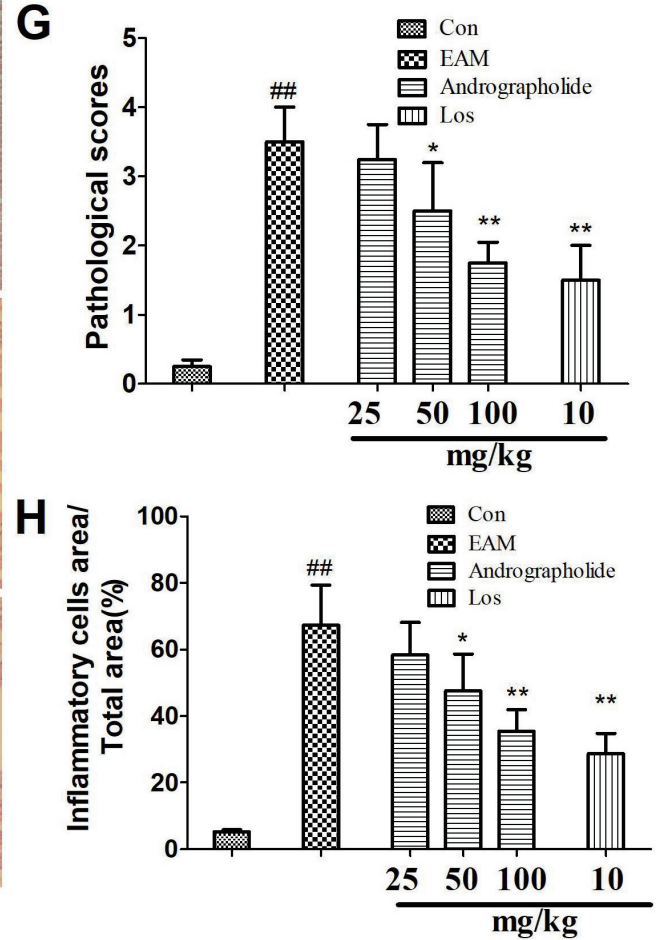

Fig. 2. Effects of andrographolide on myocardial histopathology of EAM rats. (A) Con group; (B) EAM group; (C) andrographolide $25 \mathrm{mg} / \mathrm{kg}$; (D) andrographolide $50 \mathrm{mg} / \mathrm{kg}$; (E) andrographolide $100 \mathrm{mg} / \mathrm{kg}$; (F) losartan $10 \mathrm{mg} / \mathrm{kg}$; (G) pathological scores were evaluated by professional staff. Results are presented as the mean \pm S.D. $N=6-9$. Con: control; EAM: experimental autoimmune myocarditis; Los: losartan. "\#p $<0.01$, compared with Con; ${ }^{*} \mathrm{p}<0.05,{ }^{* *} \mathrm{p}<0.01$, compared with EAM. 
rats.

\section{Effects of andrographolide on myocardial inflammatory response in EAM rats}

Histological examination showed a lot of inflammatory cells infiltrated in the myocardial tissue. Therefore, we further inves- tigated effects of andrographolide on infiltration of $\mathrm{T}$ cells and monocytes using immunohistochemical analysis. As shown in Fig. 3 and Fig. 4, compared with rats in control group, vehicletreated EAM rats showed increased numbers of positive $\mathrm{CD}^{+}$ and $\mathrm{CD} 14^{+}$cells in the tissue $(\mathrm{p}<0.01)$, suggesting enhanced myocardial inflammatory response. However, andrographolide significantly reduced the numbers of positive $\mathrm{CD}^{+}$and $\mathrm{CD} 14^{+}$
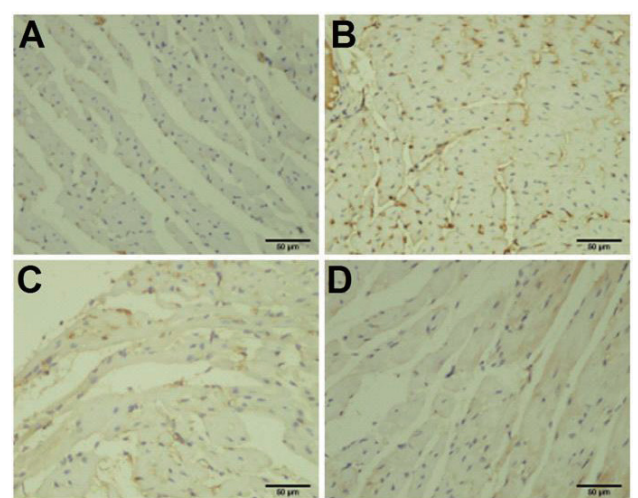

E

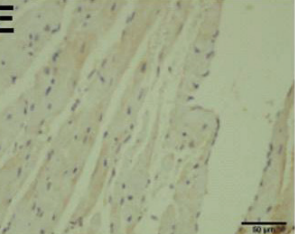

$\mathbf{F}$

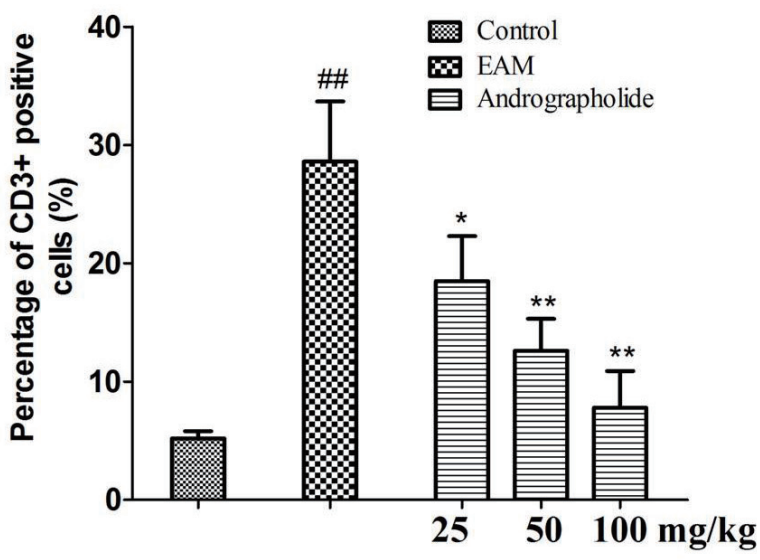

Fig. 3. Effects of andrographolide on the numbers of $C D 3^{+}$positive cells in myocardium of EAM rats. (A) Con group; (B) EAM group; (C) andrographolide $25 \mathrm{mg} / \mathrm{kg}$; (D) andrographolide $50 \mathrm{mg} / \mathrm{kg}$; (E) andrographolide $100 \mathrm{mg} / \mathrm{kg}$; (F) the numbers of CD3 ${ }^{+}$positive cells were determined in ten randomly selected fields by a professional staff, who didn't know grouped details. Results are presented as the mean \pm S.D. $N=6-9$. Con: control; EAM: experimental autoimmune myocarditis; ${ }^{\# \#}<0.01$, compared with Con; ${ }^{*} p<0.05,{ }^{* *} p<0.01$, compared with EAM.
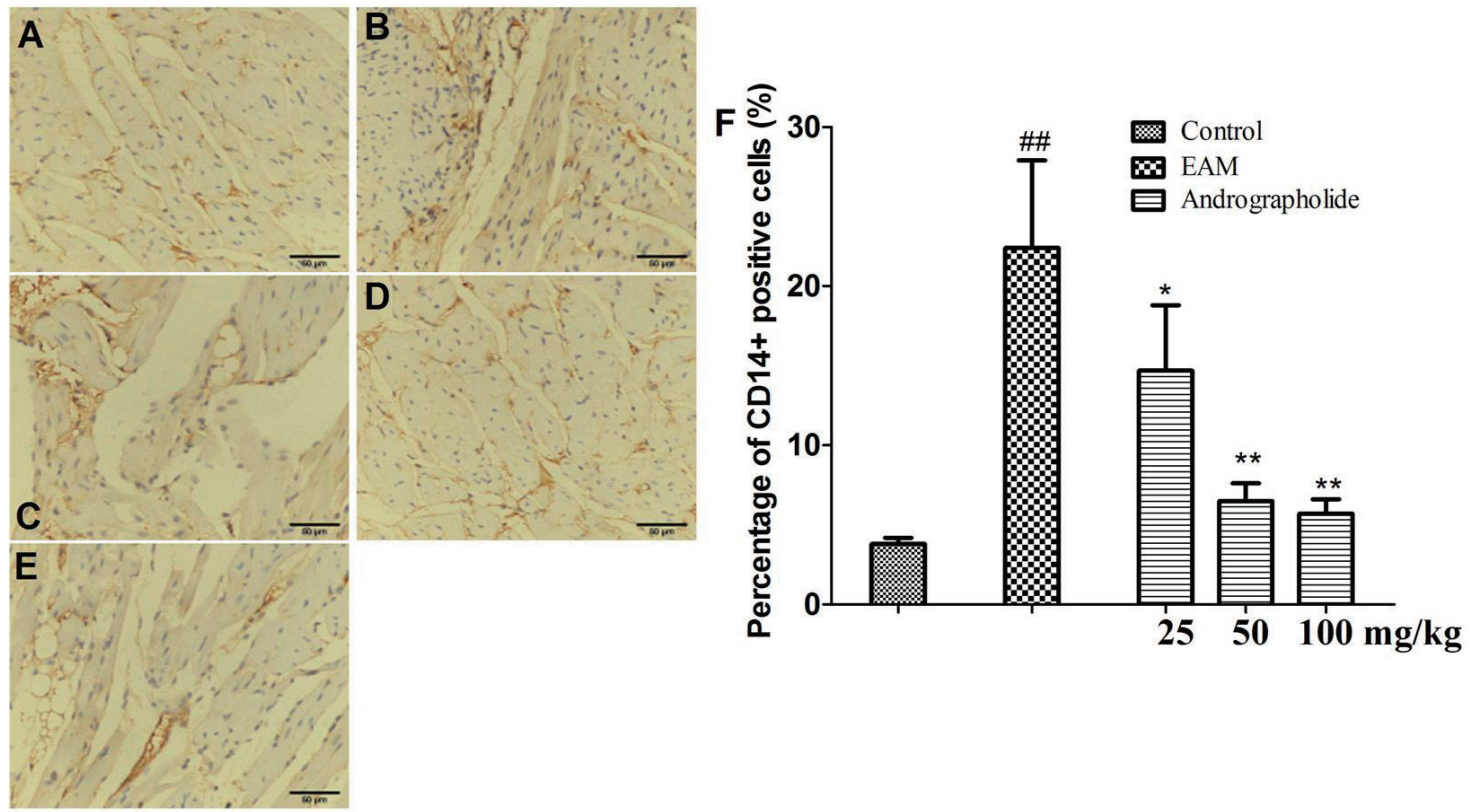

Fig. 4. Effects of andrographolide on the numbers of CD14 positive cells in myocardium of EAM rats. (A) Con group; (B) EAM group; (C) andrographolide $25 \mathrm{mg} / \mathrm{kg}$; (D) andrographolide $50 \mathrm{mg} / \mathrm{kg}$; (E) andrographolide $100 \mathrm{mg} / \mathrm{kg}$; (F) the numbers of CD14 positive cells were determined in ten randomly selected fields by a professional staff, who didn't know grouped details. Results are presented as the mean \pm S.D. $N=6-9$. Con: control; EAM: experimental autoimmune myocarditis; ${ }^{* *} p<0.01$, compared with Con; ${ }^{*} p<0.05,{ }^{* *} p<0.01$, compared with EAM. 
cells in myocardial tissue $(\mathrm{p}<0.01)$. Moreover, we have detected plasma inflammatory cytokines and anti-myosin antibody in all rats by ELISA kits. As seen in Fig. 5, compared with EAM group, andrographolide oral administration significantly reduced the levels of TNF-alpha, IL-17 and anti-myosin ( $\mathrm{p}<0.01)$. In contrast, the production of IL-10 was significantly elevated in the andrographolide-treated group compared with the vehicle-treated group $(\mathrm{p}<0.01)$.

\section{Effects of andrographolide on PI3K/Akt signaling pathway in EAM rats}

As seen in Fig. 6, expressions of p-PI3K and p-Akt were obviously increased in vehicle-treated EAM rats compared with that of control rats $(\mathrm{p}<0.01)$. In the andrographolide groups, the myocardial levels of p-PI3K and p-Akt were significantly reduced compared with that of EAM group $(\mathrm{p}<0.01)$. Moreover, we found andrographolide treatment had no effects on the total expression of PI3K and Akt in EAM rats.

\section{Effects of andrographolide on myosin-induced splenocytes proliferation}

To study whether andrographolide directly inhibits cardiac myosin-induced activation in lymphocytes, we performed a
MTT assay to examine effects of andrographolide on myosininduced proliferation in splenocytes. As seen in Fig. 7, myosin significantly stimulated splenocytes proliferation $(\mathrm{p}<0.01)$, and the effect of myosin was significantly inhibited by co-treatment of andrographolide ( $\mathrm{p}$ 0.01). However, an Akt activator, SC79, significantly inhibited andrographolide-induced inhibitory effects on proliferation of splenocytes (Fig. 7, p < 0.05). Finally, the data from western blotting indicated SC79 treatment effectively increased the expression of $\mathrm{p}$-Akt in andrographolide-treated cells (Fig. 7, p < 0.01).

\section{DISCUSSION}

In this study, we investigated the effects of andrographolide in a rat model of EAM. Treatment with andrographolide reduced mortality rates, improved cardiomyopathology and cardiac functions. Our result is consistent with previous reports that concluded andrographolide showed a well protective action in cardiovascular diseases. In previous studies, Zhang et al. [15] reported andrographolide attenuates LPS-induced cardiac malfunctions. Hsieh et al. [10] found andrographolide displays inhibitory effects on cardiac hypertrophy and myocardial apoptosis in highfat diet fed mice. Woo et al. [16] have confirmed andrographolide protected cardiomyocytes against hypoxia/reoxygenation injury.
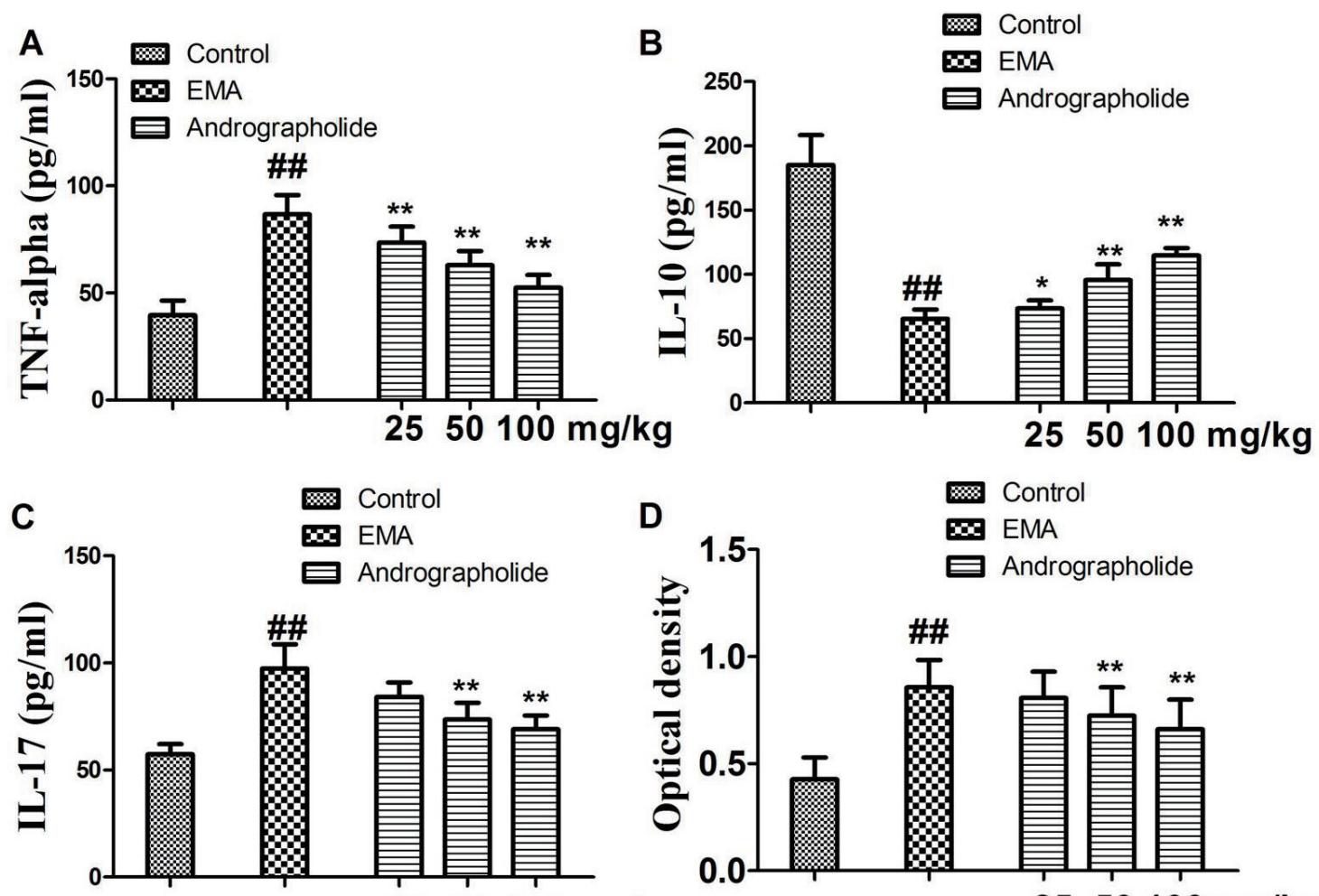

D
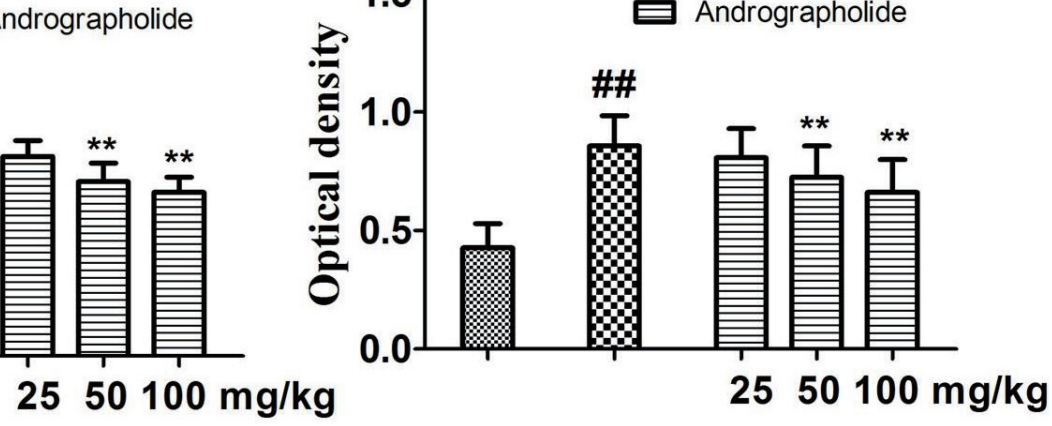

Fig. 5. Effects of andrographolide on the levels of inflammatory cytokines and myosin antibody in EAM rats. (A) TNF-alpha; (B) IL-10; (C) IL-17; (D) myosin antibody. Results are presented as the mean \pm S.D. $N=6-9$. EAM: experimental autoimmune myocarditis; $\#$ $p<0.01$, compared with Control; ${ }^{*} p<0.05,{ }^{* *} p<0.01$, compared with EAM. 


\section{Andrographolide}

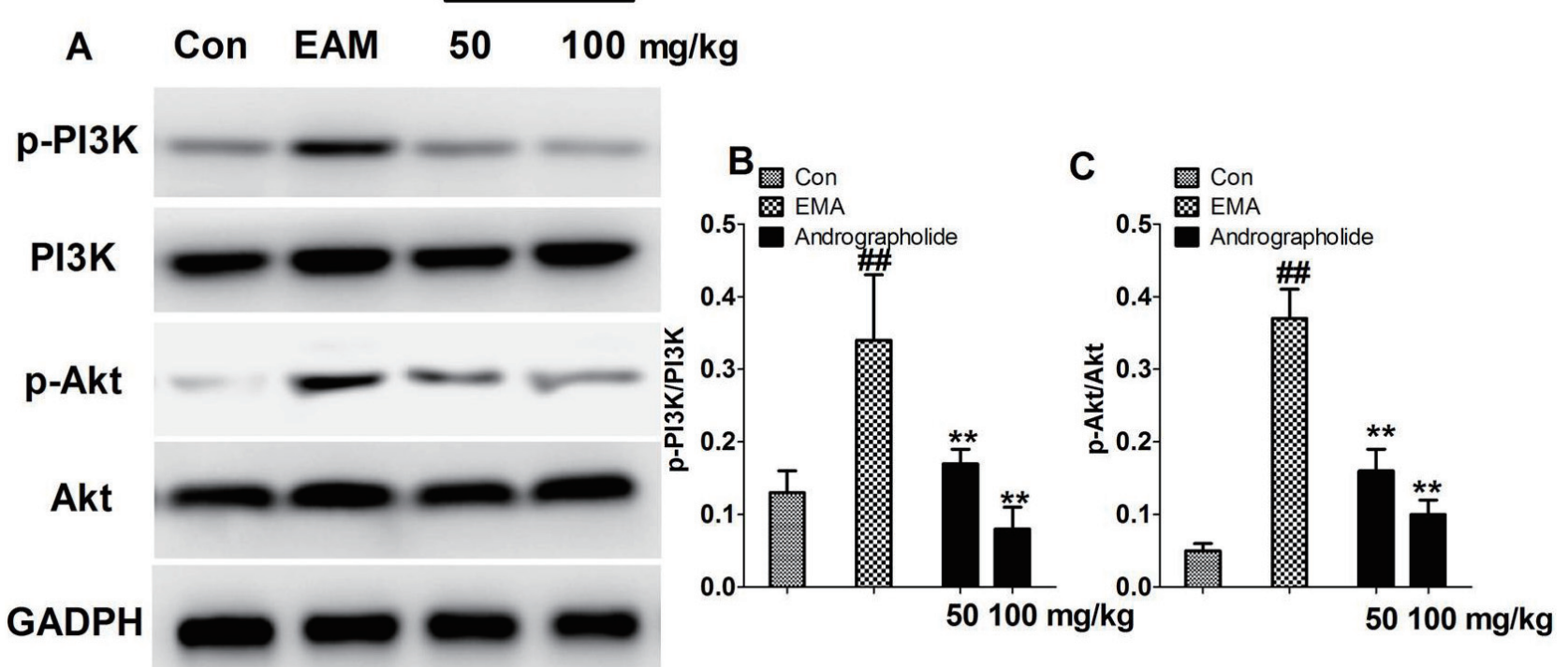

Fig. 6. Effects of andrographolide on PI3K/Akt pathway. (A) Representative stripes; $(\mathrm{B}, \mathrm{C})$ the stripes were quantitatively analyzed by Image J. Results are showed as the mean \pm S.D. $N=6-9$. Con: control; EAM: experimental autoimmune myocarditis. ${ }^{\# \#} \mathrm{p}<0.01$, compared with Con; ${ }^{* *} \mathrm{p}<0.01$, compared with EMA.

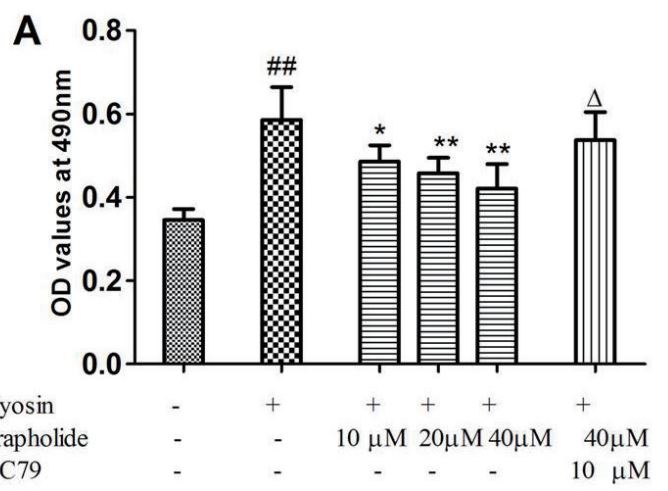

B1

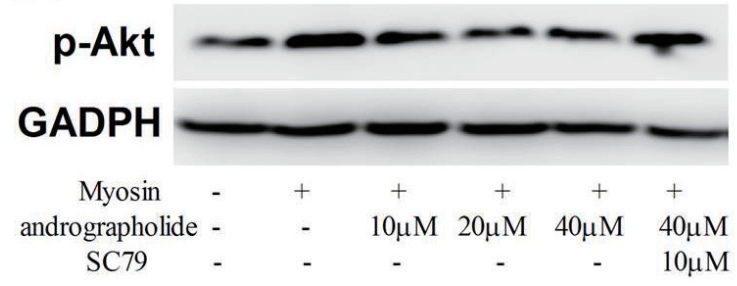

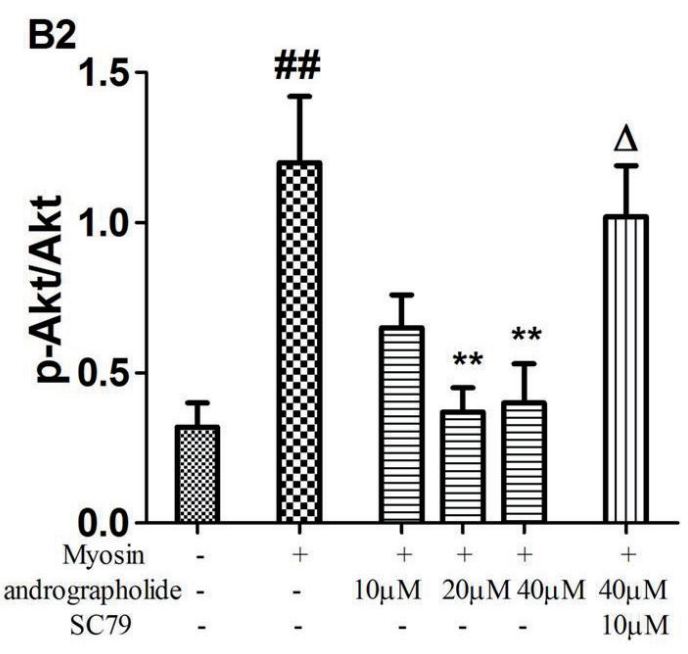

Fig. 7. Effects of andrographolide on proliferation of myosin-treated splenetic cells. (A) Splenetic cells were collected from EAM rats, and treated with andrographolide in the presence and absence of SC79 for $48 \mathrm{~h}$. Myosin-specific proliferative responses were measured by MTT colorimetric technique. (B1) typical p-Akt stripes; (B2) the stripes were quantitatively analyzed by image j. Results are presented as the mean \pm S.D. $N=3$. Con: control; EAM: experimental autoimmune myocarditis. ${ }^{\# \#} p<0.01$, compared with splenetic cells without treatment; ${ }^{*} p<0.05,{ }^{* *} p<0.01$, compared with splenetic cells only treated with myosin $(20 \mu \mathrm{g} / \mathrm{ml}) ;{ }^{\wedge} \mathrm{p}<0.05$, compared with the cells treated with myosin and andrographolide $(40 \mu \mathrm{M})$.

Our data firstly prove protective action of andrographolide in the EAM model.

Inflammatory response play important roles in the progression of cardiovascular diseases. At the beginning of EAM, the injected myosin attacks myocardial tissue, and thereby activates cardiac resided immune cells or the circulating cells that migrated to myocardium [3]. Some studies showed cardiac antigen-specific naïve T cells, especially those specific of $\alpha$-myosin heavy chain peptides, become activated and differentiate into expanded clones of effector T cells under various conditions, such as cardiac in- 
fection and/or genetic variations in peripheral tolerance [17]. It has been previously showed monocyte control $\mathrm{T}$ cell responses against cardiac myosin in myocarditis animal models. However, exaggerated monocyte activation by cardiac myosin peptide TLR ligands in pathogenesis of myocarditis represents a two-edged sword. Monocyte-derived cytokines not only promote development of Th17 cells, but also result in the activation of TGF- $\beta$ mediated cardiac fibrosis [18]. Moreover, inflammatory cytokines secreted by monocytes and T cells, directly damage the functions of cardiomyocytes. IL-17 has been confirmed to promote cardiac fibrosis and inhibit myocardial diastolic function [19-21]. IL-10 knockout increase the sensitivity of left ventricular dysfunction to pressure overload, while IL-10 treatment improve left ventricular functions in rats with myocardial infarction. These effects can be explained as follows: IL-17 regulates cardiomyocytes apoptosis, while IL-10 suppresses production of inflammatory cytokines in rat cardiomyocytes, and attenuates TNF-alpha-induced cardiomyocytes apoptosis [22,23]. Moreover, TNF-alpha induces apoptosis in cardiomyocytes and promotes cardiac inflammation and fibrosis $[24,25]$. In present study, andrographolide treatment significantly inhibited infiltration of $\mathrm{CD}^{+}$positive $\mathrm{T}$ cells and $\mathrm{CD}_{4} 4^{+}$positive monocytes in EAM rats. Moreover, andrographolide reduced circulating levels of TNF-alpha, IL-17 and myosin-antibody. Our data suggest andrographolide improves myosin-induced inflammation in EAM rats. It should be noted that andrographolide has an excellent anti-inflammatory activity. In vitro study, andrographolide has been reported to suppress production of a lot of inflammatory cytokines, chemokines and enzymes in immune cells (macrophages, fibroblasts) and human bronchial epithelial cells [8]. In vivo studies, andrographolide has been confirmed to exhibit powerful anti-inflammatory effects in animal models of pulmonary fibrosis, allergic airway and diabetic nephropathy [26-28].

$\mathrm{PI} 3 \mathrm{~K} / \mathrm{Akt}$ is an important signaling pathway in the regulation of inflammatory response. The pathway comprises of two main driving molecules: PI3K and Akt. PI3K could be activated by receptor tyrosine kinases and $\mathrm{G}$ protein-coupled receptors, forming p-PI3K. Following PI3K activation and serial cascade reactions, Akt is phosphorylated, and eventually triggers multiple downstream pathways involved in protein synthesis, cell proliferation, metabolism and survival [5]. Previous studies confirmed cardiacrestricted over-expression of either PI3K $\alpha$ or its upstream IGF1 receptor resulted in increased cardiomyocytes size and larger hearts. Constitutive activation of Akt increased cardiomyocytes size and led to concentric left ventricle hypertrophy, while Akt knockout mice displayed smaller heart [29-32]. Moreover, cardiac-specific activation of Akt promoted vascular endothelial growth factor and angiopoietin-2 expression in cardiomyocytes, and ultimately increased myocardial capillary density and physiological hypertrophic remodeling [33]. PI3K inhibitor ameliorates the symptom of myosin-induced myocarditis in mice [7], suggesting the pathway is the potential therapeutic target of myocarditis.
Andrographolide has been proposed to be an anti-inflammatory medicine with multiple targets, including NF- $\kappa \mathrm{B}$, MAPKs and JAK/STAT pathways [8]. Moreover, andrographolide has been reported to inhibit inflammatory response in TNF-alpha-treated HUVEC cells by down-regulation of PI3K/Akt pathway, and attenuate TNF-alpha-induced ICAM-1 expression with an PI3K/ Akt pathway-dependent manner [34,35]. To confirm the role of PI3K/Akt pathway in protective bioactivity of andrographolide against EAM, we analyzed expression of PI3K, p-PI3K, Akt and p-Akt in the cardiac tissue. The results showed andrographolide significantly reduced cardiac levels of p-PI3K and p-Akt without any change of PI3K and Akt. Interestingly, we noted SC79 significantly reduced andrographolide-induced inhibitory effects on proliferation of the splenocytes.

In conclusion, our results demonstrate protective effects of andrographolide on EAM model were primarily associated with suppression of cardiac inflammation and blockade of PI3K/Akt pathway. Our findings indicate the potential value of andrographolide for treating human myocarditis.

\section{ACKNOWLEDGEMENTS}

This work was supported by the Anhui Province Nature Science Foundation in the University (kj2013z125).

\section{CONFLICTS OF INTEREST}

The authors declare no conflicts of interest.

\section{REFERENCES}

1. Drory Y, Turetz Y, Hiss Y, Lev B, Fisman EZ, Pines A, Kramer MR. Sudden unexpected death in persons less than 40 years of age. Am J Cardiol. 1991;68:1388-1392.

2. Cooper LT Jr, Keren A, Sliwa K, Matsumori A, Mensah GA. The global burden of myocarditis: part 1: a systematic literature review for the global burden of diseases, injuries, and risk factors 2010 study. Glob Heart. 2014;9:121-129.

3. Sagar S, Liu PP, Cooper LT Jr. Myocarditis. Lancet. 2012;379:738747.

4. Elamm C, Fairweather D, Cooper LT. Pathogenesis and diagnosis of myocarditis. Heart. 2012;11:835-840.

5. Ghigo A, Li M. Phosphoinositide 3-kinase: friend and foe in cardiovascular disease. Front Pharmacol. 2015;6:169.

6. Yu P, Zhang Y, Li C, Li Y, Jiang S, Zhang X, Ding Z, Tu F, Wu J, Gao $\mathrm{X}$, Li L. Class III PI3K- mediated prolonged activation of autophagy plays a critical role in the transition of cardiac hypertrophy to heart failure. JCell Mol Med. 2015;19:1710-1719.

7. Liu HS, Zhang J, Guo JL, Lin CY, Wang ZW. Phosphoinositide 3-kinase inhibitor LY294002 ameliorates the severity of myosin-induced myocarditis in mice. Curr Res Transl Med. 2016;64:21-27. 
8. Lim JC, Chan TK, Ng DS, Sagineedu SR, Stanslas J, Wong WS. Andrographolide and its analogues: versatile bioactive molecules for combating inflammation and cancer. Clin Exp Pharmacol Physiol. 2012;39:300-310.

9. He CL, Yi PF, Fan QJ, Shen HQ, Jiang XL, Qin QQ, Song Z, Zhang C, Wu SC, Wei XB, Li YL, Fu BD. Xiang-Qi-Tang and its active components exhibit anti-inflammatory and anticoagulant properties by inhibiting MAPK and NF- $\kappa \mathrm{B}$ signaling pathways in LPS-treated rat cardiac microvascular endothelial cells. Immunopharmacol Immunotoxicol. 2013;35:215-224.

10. Hsieh YL, Shibu MA, Lii CK, Viswanadha VP, Lin YL, Lai CH, Chen YF, Lin KH, Kuo WW, Huang CY. Andrographis paniculata extract attenuates pathological cardiac hypertrophy and apoptosis in high-fat diet fed mice. JEthnopharmacol. 2016;192:170-177.

11. Lee YC, Lin HH, Hsu CH, Wang CJ, Chiang TA, Chen JH. Inhibitory effects of andrographolide on migration and invasion in human non-small cell lung cancer A549 cells via down-regulation of PI3K/ Akt signaling pathway. Eur J Pharmacol. 2010;632:23-32.

12. Wang W, Wang J, Dong SF, Liu CH, Italiani P, Sun SH, Xu J, Boraschi D, Ma SP, Qu D. Immunomodulatory activity of andrographolide on macrophage activation and specific antibody response. Acta Pharmacol Sin. 2010;31:191-201.

13. Veeraveedu PT, Watanabe K, Ma M, Thandavarayan RA, Palaniyandi SS, Yamaguchi K, Suzuki K, Kodama M, Aizawa Y. Comparative effects of torasemide and furosemide in rats with heart failure. Biochem Pharmacol. 2008;75:649-659.

14. Liu X, Zhang X, Ye L, Yuan H. Protective mechanisms of berberine against experimental autoimmune myocarditis in a rat model. Biomed Pharmacother. 2016;79:222-230.

15. Zhang J, Zhu D, Wang Y, Ju Y. Andrographolide attenuates LPSinduced cardiac malfunctions through inhibition of $I_{\kappa} B$ phosphorylation and apoptosis in mice. Cell Physiol Biochem. 2015;37:16191628.

16. Woo AY, Waye MM, Tsui SK, Yeung ST, Cheng CH. Andrographolide up-regulates cellular-reduced glutathione level and protects cardiomyocytes against hypoxia/reoxygenation injury. J Pharmacol Exp Ther. 2008;325:226-235.

17. Lichtman AH. The heart of the matter: protection of the myocardium from T cells. J Autoimmun. 2013;45:90-96.

18. Myers JM, Cooper LT, Kem DC, Stavrakis S, Kosanke SD, Shevach EM, Fairweather D, Stoner JA, Cox CJ, Cunningham MW. Cardiac myosin-Th17 responses promote heart failure in human myocarditis. JCI Insight. 2016;1(9):e85851.

19. Liu Y, Zhu H, Su Z, Sun C, Yin J, Yuan H, Sandoghchian S, Jiao Z, Wang S, Xu H. IL-17 contributes to cardiac fibrosis following experimental autoimmune myocarditis by a PKC $\beta /$ Erk1/2/NF- $\mathrm{B}$ dependent signaling pathway. Int Immunol. 2012;24:605-612.

20. Stumpf C, Seybold K, Petzi S, Wasmeier G, Raaz D, Yilmaz A, Anger T, Daniel WG, Garlichs CD. Interleukin-10 improves left ventricular function in rats with heart failure subsequent to myocardial infarction. Eur J Heart Fail. 2008;10:733-739.

21. Yu Y, Zhang ZH, Wei SG, Chu Y, Weiss RM, Heistad DD, Felder RB. Central gene transfer of interleukin-10 reduces hypothalamic inflammation and evidence of heart failure in rats after myocardial infarction. Circ Res. 2007;101:304-312.

22. Su SA, Yang D, Zhu W, Cai Z, Zhang N, Zhao L, Wang JA, Xiang M.
Interleukin-17A mediates cardiomyocyte apoptosis through Stat3iNOS pathway. Biochim Biophys Acta. 2016;1863:2784-2794.

23. Damås JK, Aukrust P, Ueland T, Odegaard A, Eiken HG, Gullestad L, Sejersted OM, Christensen G. Monocyte chemoattractant protein-1 enhances and interleukin-10 suppresses the production of inflammatory cytokines in adult rat cardiomyocytes. Basic Res Cardiol. 2001;96:345-352.

24. Chen ZW, Qian JY, Ma JY, Chang SF, Yun H, Jin H, Sun AJ, Zou YZ, Ge JB. TNF- $\alpha$-induced cardiomyocyte apoptosis contributes to cardiac dysfunction after coronary microembolization in mini-pigs. J Cell Mol Med. 2014;18:1953-1963.

25. Duerrschmid C, Trial J, Wang Y, Entman ML, Haudek SB. Tumor necrosis factor: a mechanistic link between angiotensin-II-induced cardiac inflammation and fibrosis. Circ Heart Fail. 2015;8:352-361.

26. Guan SP, Kong LR, Cheng C, Lim JC, Wong WS. Protective role of 14-deoxy-11,12-didehydroandrographolide, a noncytotoxic analogue of andrographolide, in allergic airway inflammation. J Nat Prod. 2011;74:1484-1490

27. Ji X, Li C, Ou Y, Li N, Yuan K, Yang G, Chen X, Yang Z, Liu B, Cheung WW, Wang L, Huang R, Lan T. Andrographolide ameliorates diabetic nephropathy by attenuating hyperglycemia- mediated renal oxidative stress and inflammation via $\mathrm{Akt} / \mathrm{NF}-\kappa \mathrm{B}$ pathway. Mol Cell Endocrinol. 2016;437:268-279.

28. Yin JN, Li YN, Gao Y, Li SB, Li JD. Andrographolide plays an important role in bleomycin-induced pulmonary fibrosis treatment. Int J Clin Exp Med. 2015;8:12374-12381.

29. Condorelli G, Drusco A, Stassi G, Bellacosa A, Roncarati R, Iaccarino G, Russo MA, Gu Y, Dalton N, Chung C, Latronico MV, Napoli C, Sadoshima J, Croce CM, Ross J Jr. Akt induces enhanced myocardial contractility and cell size in vivo in transgenic mice. Proc Natl Acad Sci U S A. 2002;99:12333-12338.

30. DeBosch B, Treskov I, Lupu TS, Weinheimer C, Kovacs A, Courtois $\mathrm{M}$, Muslin AJ. Akt1 is required for physiological cardiac growth. Circulation. 2006;113:2097-2104.

31. McMullen JR, Shioi T, Huang WY, Zhang L, Tarnavski O, Bisping E, Schinke M, Kong S, Sherwood MC, Brown J, Riggi L, Kang PM, Izumo $S$. The insulin-like growth factor 1 receptor induces physiological heart growth via the phosphoinositide 3-kinase(p110a) pathway. J Biol Chem. 2004;279:4782-4793.

32. Shioi T, Kang PM, Douglas PS, Hampe J, Yballe CM, Lawitts J, Cantley LC, Izumo S.The conserved phosphoinositide 3-kinase pathway determines heart size in mice. EMBO J. 2000;19:2537-2548.

33. Shiojima I, Sato K, Izumiya Y, Schiekofer S, Ito M, Liao R, Colucci WS, Walsh K. Disruption of coordinated cardiac hypertrophy and angiogenesis contributes to the transition to heart failure. J Clin Invest. 2005;115:2108-2118.

34. Chen HW, Lin AH, Chu HC, Li CC, Tsai CW, Chao CY, Wang CJ, Lii CK, Liu KL. Inhibition of TNF- $\alpha$-Induced inflammation by andrographolide via down-regulation of the PI3K/Akt signaling pathway. J Nat Prod. 2011;74:2408-2413.

35. Lu CY, Yang YC, Li CC, Liu KL, Lii CK, Chen HW. Andrographolide inhibits TNF $\alpha$-induced ICAM-1 expression via suppression of NADPH oxidase activation and induction of HO-1 and GCLM expression through the PI3K/Akt/Nrf2 and PI3K/Akt/AP-1 pathways in human endothelial cells. Biochem Pharmacol. 2014;91:4050 . 